J. Clin. Chem. Clin. Biochem.

Vol. 26, 1988, pp. 255-258

(C) 1988 Walter de Gruyter \& Co. Berlin - New York

\title{
Glutathione Peroxidase Activity, Lipid Peroxides and Selenium Status in Blood in Patients with Down's Syndrome
}

\author{
By Jolanta Gromadzińska, W. Wasowicz, Maria Sklodowska
}

Department of Biochemistry, Medical Academy Lódź, Poland and

H. Stróżyński

Department of Biology, Medical Academy Lódź, Poland

(Received December 22, 1986/November 17, 1987)

Summary: The concentrations of selenium and lipid peroxides and the catalytic activity of glutathione peroxidase were measured in the blood of 6 children (6-16 years of age) and 8 adults (17-27 years old) with Down's syndrome (trisomy 21). The values were compared with those for a control group of age-matched normal people.

The selenium concentration in whole blood, erythrocytes and plasma was significantly lower in trisomy 21 patients than in normal subjects $(p<0.001)$ in both age groups. No statistically significant differences were observed in selenium concentration in whole blood, erythrocytes and plasma between children and adults in the Down's syndrome group. Glutathione peroxidase catalytic activity in erythrocytes was significantly higher in Down's syndrome children than in healthy children $(\mathrm{p}<0.001)$. Plasma glutathione peroxidase catalytic activity in both investigated age groups was statistically considerably lower in the Down's syndrome patient group. The concentration of lipid peroxides, expressed as the malondialdehyde concentration, is lower in Down's syndrome patients. No correlation between selenium concentration, glutathione peroxidase catalytic activity and amount of lipid peroxides was found in the trisomy 21 patient group.

\section{Introduction}

Many papers have repórted investigations of oxygen metabolism in trisomy 21 patients (Down's syndrome) and there have been suggestions that some of the pathological symptoms of this disease, for example premature ageing, or specific brain lesion, result from the increase of the oxidative damage inside the cells $(1,2)$. One of the observed and probable defence mechanisms of the cell against the oxidative damage is the increase of catalytic activity of enzymes counteracting toxic oxygen derivatives: superoxide dismutase (EC 1.15.1.1), and glutathione peroxidase (EC 1.11.1.9) $(2,3)$. Glutathione peroxidase catalyses the reduction of hydrogen peroxide and organic hydroperoxides to alcohols of lower toxicity, thus forming the first line of defence against peroxidative damage of unsaturated lipids (4).
Selenium (Se) is necessary for the enzymatic activity of glutathione peroxidase - it is the component of the catalytic site of the enzyme (5) and probably stimulates glutathione peroxidase synthesis in humans (6) and animals (7). The gene for glutathione peroxidase synthesis is situated on chromosome No. 3 and for this reason the increase of the glutathione peroxidase activity in trisomy 21 patients is not caused by a gene dosage effect (8). The higher activity of the enzyme in the cells may be explained as one of the mechanisms controlling the response to an acceleration of oxidative processes inside the trisomic 21 cells.

Anneren et al. (9) observed that the superoxide concentration in polymorphonuclear neutrophils from Down's syndrome patients is only about $75 \%$ of that in healthy individuals. This decrease in superoxide 
concentration is probably due to an increased transformation of superoxide anion to $\mathrm{H}_{2} \mathrm{O}_{2}$, and might be one of the possible explanations for the fact that glutathione peroxidase activity is increased in Down's syndrome patients.

The erythrocyte glutathione peroxidase catalytic activity in trisomy 21 patients, however, remains a matter of controversy: normal activities have been claimed by some authors $(1,10)$, and elevated activities by others $(2,11,12,13,14)$. Until now there has been only one report of an increase of lipid peroxide concentration in the plasma of patients with Down's syndrome (13).

The aim of our work was to determine relationships between glutathione peroxidase activity and selenium and lipid peroxide concentrations in Down's syndrome patients in 2 age groups, in comparison with agematched normal people.

\section{Materials and Methods}

The investigation was carried out upon 14 Down's syndrome patients ( 8 females, 6 males with karyotypes $47, X X+21$ and $47, X Y+21$, respectively) living in Łódź. The trisomy 21 patients were out-patients who visit the clinics regularly. The control group consisted of 110 people aged $6-30$ years (57 males and 53 females) from Łódź and its surroundings.

All patients and controls had normal haematological values (haemoglobin concentration, haematocrit, red blood cell count). Venous blood samples were collected in heparinized tubes free from trace-elements. Plasma and buffy coat were removed after centrifugation and red blood cells were washed twice with isotonic saline. Pure erythrocytes were suspended in $9 \mathrm{~g} / \mathrm{l}$ saline, then lysed by freezing and thawing.

The activity of glutathione peroxidase in plasma and erythrocytes was estimated by the Paglia \& Valentine method (15) modified by Hopkins \& Tudhope (16), with the use of $t$-butyl hydroperoxide as a substrate.

Glutathione peroxidase activity was defined as the amount of enzyme which catalyses oxidation of $1 \mu \mathrm{mol}$ of NADPH per min per $\mathrm{g}$ of $\mathrm{Hb}$ (or $\mathrm{l}$ of plasma). Selenium was determined by the fluorimetric method of Watkinson (17) with 2,3-diaminonaphthalene. Quality control was monitored by the use of the International Atomic Energy Agency dried blood standard (A13 ) and the selenium content (mean \pm SD) determined in this study was $255 \pm 15 \mu \mathrm{g} / \mathrm{kg}$ the assigned value being $240 \mu \mathrm{g} / \mathrm{kg}$. Se concentration was expressed in $\mu \mathrm{g}$ of selenium per l of whole blood, plasma or pure packed erythrocytes. The concentration of peroxides of higher polyunsaturated fatty acids was determined in plasma by the Yagi method (18) with 2-thiobarbituric acid. 1,1,3,3-Tetraethoxypropane $(0.5 \mathrm{~mol} / \mathrm{l})$ was used as a standard. The concentration of lipid peroxides in blood plasma was expressed as the amount of malondialdehyde per 1 of plasma.

Haemoglobin concentrations were determined by the haemiglobin cyanide method. Differences between group means were tested by the Student t-test.

\section{Results}

The results are presented in table 1.

Selenium concentration in whole blood, erythrocytes and in plasma was significantly lower in the Down's syndrome patients than in normal subjects $(\mathrm{p}<0.001$ in all cases) in both investigated age groups.

Tab. 1. Lipid peroxides and selenium concentration and glutathione peroxidase activity in blood of patients with Down's syndrome and controls. The number of observations are shown in parenthesis.

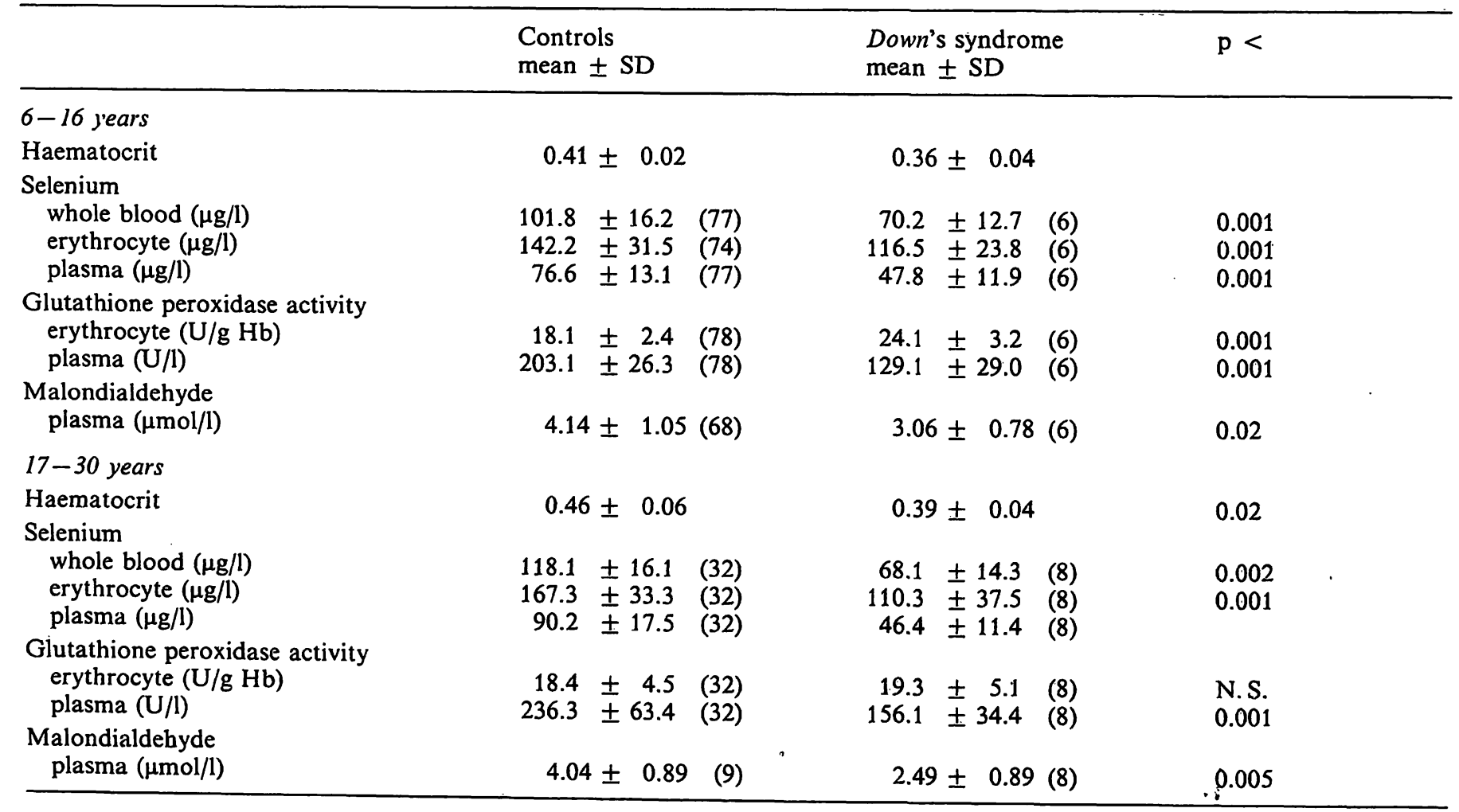


In the control group (aged 17-27 years) the selenium concentrations in whole blood, erythrocytes and plasma were statistically higher than in the group of healthy children $(6-16$ years $)(p<0.001)$. No statistical differences between children (6-16 years) and adults (17-27 years) were found in the trisomy 21 group with respect to the selenium concentration in whole blood, erythrocytes and plasma.

No sex differences between the control and patient groups were found. Glutathione peroxidase activity in erythrocytes is significantly increased in trisomy 21 children ( $p<0.001$ ), but in the adult group no statistically significant differences were noticed between the Down's syndrome patients and control group.

However, the plasma enzyme activity in both tested groups is statistically significantly decreased in the Down's syndrome patient group $(\mathrm{p}<0.001$ in both groups). The concentration of lipid peroxides, as expressed by malondialdehyde, is lower in trisomy 21 patients. This decrease is statistically significant in the group of children and adults: $p<0.02$ and $p<0.005$, respectively. No correlation was found between lipid peroxide concentration. and the corresponding glutathione peroxidase activity in erythrocytes and plasma in the Down's syndrome patient group.

\section{Discussion}

Earlier investigations have demonstrated a trend towards increasing erythrocyte glutathione peroxidase activity in trisomy 21 patients as compared with healthy control groups $(2,9,11-14)$. In our investigation we have shown a $30 \%$ increase of glutathione peroxidase catalytic activity in erythrocytes of children with Down's syndrome as compared with an agematched control group. In adult patients the erythrocyte glutathione peroxidase activity increases by $5 \%$. These values are comparable with those obtained by Neve et al. (10), and are slightly lower than those reported earlier in which glutathione peroxidase activity in Down's syndrome patients was found to be $139-156 \%$ of that in healthy controls $(11,12)$. Probably the increase of glutathione peroxidase activity in erythrocytes is the secondary result of a regulatory mechanism involving an increased activity of superoxide dismutase and intensified production of $\mathrm{H}_{2} \mathrm{O}_{2}$ in trisomy 21 cells (9). Elevated glutathione peroxidase activity in Down's syndrome patients could be a useful protective mechanism against peroxidative cell damage.

The increase of glutathione peroxidase activity in the erythrocytes of Down's syndrome patients does not result in the increase of Se concentration. Whole blood, erythrocyte and plasma selenium was significantly lower in Down's syndrome patients than in normal subjects in both tested groups. The absence of any change of Se concentrations in Down's syndrome erythrocytes can be explained by the fact that selenium, in the form of Se-glutathione peroxidase, constitutes only $10 \%$ of the total cell selenium (9). The low selenium concentration in Down's syndrome patients is not due to an insufficiency of selenium intake $(1,14,20)$. Belgium investigators $(14,20)$ have shown that control groups receiving the same food as the Down's syndrome patients have a significantly higher Se concentration in plasma. In erythrocytes the Se concentration increase is not significant. The observed decrease of Se concentration in trisomy 21 patients has no influence upon its bioavailability, as the activity of glutathione peroxidase does not differ from that of the control group $(12,13,14,20)$.

As it has been shown that the concentrations of copper and zinc in erythrocytes of Down's syndrome of patients show a statistically significant increase $(1,10$, 14, 21). The decreased concentration of selenium in erythrocytes may be explained as a result of the antagonistic activity of trace elements in the cell e.g. $\mathrm{Zn}$-Se (22). On the other hand plasma, erythrocyte and whole blood selenium deficiency could be explained as malabsorption of Se from the gastrointestinal tract and/or increased renal clearance of Se (20, 23).

Since the glutathione peroxidase is one important factor in the detoxication of organic lipid peroxides, and because of the increase of lipid peroxidation in trisomy 21 cells (24), we have investigated plasma malondialdehyde concentration in Down's syndrome patients. In our investigation we observed a decrease of malondialdehyde concentration in the plasma of trisomy 21 patients, compared with the control group in both tested age groups. The decrease was $26.1 \%$ in the younger patients and $38.4 \%$ in the adult patients. This is a surprising result, because earlier we tested institutionalized Down's syndrome patients (also inhabitants of Łódź) and we observed a 20\% increase in the lipid peroxide concentration of plasma (13).

The significant changes of lipid peroxide concentration in plasma probably result from different environmental conditions, and they represent a defensive adaptation against oxidative damage. Probably unidentified factors, such as an insufficient vitamin $E$ intake or a change in the composition or contents of some fatty acids and phospholipids in the diet or in the cells, also play an important role in the change of the lipid peroxide concentration $(10,25)$. 


\section{References}

1. Vertongen, F., Neve, J., Cauchie, P. \& Molle, L. (1984), In: "Trace element - analytical chemistry in medicine and biology", vol. 3 (Brätter, P. \& Schramel, P., eds.) pp. 175181, Walter de Gruyter, Berlin-New York.

2. Sinet, P. M., Michelson, A. M., Bazin, A. \& Lejeune, J. (1975) Biochem. Biophys. Res. Commun. 67, 910-915.

3. Sinet, P. M., Michelson, A. M., Bazin, A., Lejeune, J. \& Jerome, H. (1975) Biochem. Biophys. Res. Commun. 67, 904-909.

4. Little, C. \& O'Brien, B. J. (1968) Biochem. Biophys. Res. Commun. 31, 145-150.

5. Condell, R. A. \& Tappel, A. L. (1982) Biochim. Biophys. Acta 709, 304-309.

6. Lombeck, I., Kasperek, K., Bachmann, L. E. \& Bremer, H. J. (1980) Eur. J. Pediatr. 134, 65-68.

7. Zachara, B., Gromadzińska, J., Wąsowicz, W. \& Skłodowska, M. (1984) Bull. Pol. Acad. Sci. 32, 111-118.

8. Evans, H. J., Hamerton, J. L. \& Klinger, H. P. (1979) Cytogenet. Cell. Genet. 25, 1-236.

9. Anneren, G., Edqvist, I. E. \& Gebre-Medhim, M. (1984) Trisomy $211,9-17$.

10. Neve, J., Vertongen, F., Cauchie, P., Gnat, D. \& Molle, L. (1984) J. Ment. Defic. Res. 28, 261-268.

11. Sinet, P. M., Lejeune, J. \& Jerome, H. (1979) Life Sci. 24, $29-34$.

12. Kędziora, J., Łukaszewicz, R., Koter, M., Bartosz, G., Pawłowska, B. \& Aitkin, D. (1982) Experientia 38, 543544.
13. Kędziora, J., Bartosz, G., Gromadzińska, J. Skłodowska, M., Wąsowicz, W. \& S̀cianowski, J. (1986) Clin. Chim. Acta 154, 191-194.

14. Neve, J., Sinet, P. M., Molle, L. \& Nicole, A. (1983) Clin. Chim. Acta 133, 209-214.

15. Paglia, D. E. \& Valentine, W. N. (1967) J. Lab. Clin. Med. $70,158-169$.

16. Hopkins, J. \& Tudhope, G. R. (1973) Br. J. Hematol. 25, $563-575$.

17. Watkinson, J. H. (1966) Anal. Chem. 38, 92-97.

18. Yagi, K. (1976) Biochem. Med. 15, 212-216.

19. Schmidt, K. \& Heller, W. (1976) Blut 33, 247-251.

20. Sinet, P. M., Neve, J., Nicole, A. \& Molle, L. (1984) Acta Paediatr. Scand. 73, 275-277.

21. Neve, J., Molle, L., Hanocq, M., Sinet, P. M. \& van Geffel, B. (1984) Biol. Trace Elem. Res. 5, 75-79.

22. Schrauzer, G. N. (1987) In: "Trace element - analytical chemistry in medicine and biology", vol. 4 (Brätter, P. \& Schramel, P., eds.) pp. 403-417, Walter de Gruyter, Berlin.

23. Barlow, P. J., Sylvester, P. E. \& Dickerson, J. W. T. (1981) J. Ment. Defic. Res. 25, 161.

24. Anneren, G. \& Epstein, Ch. J. (1987) Pediatr. Res. 21, $88-92$.

25. Brooksbank, B. W. L. \& Balaza, R. (1984) Dev. Brain Res. $16,37-44$.

Dr Jolanta Gromadzińska

Department of Biochemistry WAM

Medical Academy

Plac 9 Maja 1

PL-90-647 Łódź 